\title{
Depression literacy among Australians of Chinese-speaking background in Melbourne, Australia
}

\author{
Fu Keung Daniel Wong ${ }^{1 *}$, Yuk Kit Angus Lam², Ada Poon ${ }^{3}$
}

\begin{abstract}
Background: This study investigated the knowledge of depression and preference for professional help, medications and treatment methods among Australians of Chinese-speaking background, and the perceptions of this population of the causes of mental illness.

Methods: Adopting a cluster convenience sampling method, the study recruited 200 Chinese-speaking subjects from four major areas in metropolitan Melbourne where many Chinese live. The respondents were presented with a vignette describing an individual with depression and then asked questions to assess their understanding of depression and preference for professional help, medications and treatment methods. A comparative approach was used to compare the findings with those of a previous study of the mental health literacy of Australian and Japanese adults.

Results: Compared to the Australian and Japanese samples, a much lower percentage of Chinese-speaking Australians (14\%) could correctly identify major depression described in the vignette, and a higher percentage believed that counseling professionals could be helpful. Higher percentages of those who believed that close family members could be helpful were found in the Chinese-speaking Australian and Japanese samples, and these two groups also expressed more uncertainty about the usefulness or harmfulness of certain medications compared to the Australian sample. Higher percentages of respondents in both the Chinese-speaking Australian and the Australian sample considered "lifestyle changes" to be helpful compared to the Japanese sample. In the Chinesespeaking sample, 30\%, 17.4\%, 33\% and 27\% of the respondents rated "traditional Chinese medicine doctors," "Chinese herbal medications," "taking Chinese nutritional foods/supplements" and "qiqong" as helpful. Many perceived "changing fungshui" and "traditional Chinese worship" to be harmful. Regarding the perception of causes of mental illness, items related to psychosocial perspectives including "life stress" and "interpersonal conflict" were rated highly by the respondents, whereas traditional beliefs including "punishment for misdeeds conducted by ancestors" and "demon possession" had the lowest ratings.

Conclusions: Campaigns to increase the mental health literacy of Chinese-speaking Australians are needed. The abovementioned socially and culturally driven beliefs need to be taken into consideration in the development of culturally relevant education programs.
\end{abstract}

\section{Background}

Australia is a culturally diverse nation - $43 \%$ of Australians were born overseas or have at least one parent who was born overseas [1]. Besides English, the most commonly spoken languages in the country are Italian, Greek, Cantonese, Arabic, Vietnamese and Mandarin.

\footnotetext{
* Correspondence: fwong@unimelb.edu.au

${ }^{1}$ School of Nursing and Social Work, Faculty of Medicine, Dentistry and Health Sciences, University of Melbourne, Level 5, 234 Queensberry Street, Carlton, Melbourne, Victoria, 3053, Australia
}

The latest census shows that there are 206,590, 71,800, 24,370 and 39,970 China-born, Hong Kong-born, Taiwan-born and Singapore-born Chinese, respectively, who live in Australia [1]. People of Chinese-speaking background make up $3.4 \%(669,000)$ of the total Australian population. Overseas and Australian scholars have found that Asians, including Chinese, have a low rate of utilization of mental health services [2,3]. Underutilization is likely the result of a combination of personal, sociocultural and societal factors that influence whether 
or not people of culturally and linguistically diverse backgrounds seek help from mental health services. Knowledge of and beliefs surrounding mental illness and available mental health services $[4,5]$, cultural conceptions of the causes of mental illness [6,7], public and self-stigma $[8,9]$, the tendency to rely on informal networks for support [10], and practical difficulties in accessing services have been mentioned in the literature to be associated with delays in accessing mental health services [11].

Mental health literacy refers to "knowledge and beliefs about mental disorders which aid their recognition, management or prevention" [12]. Inherent in this concept is the assumption that individuals who have a higher level of mental health literacy will be more willing to seek professional help for themselves and/or for people whom they know may be suffering from a mental health problem. Jorm et al. conducted pioneer research $[5,12]$ into the mental health literacy of Australians. In one of their studies [5], they found that over $67 \%$ of the 910 Australian respondents were able to correctly identify major depression described in a case vignette, and that the percentages of those who considered a family doctor/GP or counselor, antidepressants, or physical activity helpful for treating depression were $80 \%, 48 \%$ and $92 \%$, respectively. In a Canadian study conducted by Wang et al. [13] using the same depression vignette, higher percentages of respondents correctly labeled the person in the vignette as suffering from depression (75.6\%), considered a family doctor/GP or counselor to be helpful ( $89.7 \%$ and $89.3 \%$, respectively), and said taking antidepressants or engaging in physical activities was helpful (62\% and 96.5\%, respectively). However, in general the mental health literacy of the Australian and Canadian samples was comparable.

Several studies have explored the mental health literacy of Chinese-speaking people. A study of the understanding of depression among Chinese-American women reported that $58 \%$ of the respondents believed that the person in the vignette suffered from a psychological disturbance, and only $13 \%$ failed to label the person's condition as depression [14]. In studies conducted by Parker and colleagues of Chinese-speaking Australians, the researchers found that (1) Chinese people tended to deny depression or express it somatically [15]; (2) Chinese were less likely to view a depressive episode as a disorder or to seek help for a psychological problem [16]; (3) most Chinese confided what they perceived to be private matters only to family members or close friends [17] and (4) many Chinese expected Western medications to provide an instant cure to all kinds of worries, without need for explanation as to how such drugs work [17]. In addition, respondents obtained knowledge about medications more often from friends and family than from medical professionals, and seldom asked their doctors questions about the drug they were prescribed because to do so would challenge their "authority" [17]. In a qualitative study of Chinese-speaking Australians conducted by Blignault, Ponzio, Rong and Eisenbruch [18], knowledge of mental illness, language barriers, stigma, confidentiality concerns, service constraints and discrimination were mentioned by the participants as major barriers affecting access to mental health services. These studies have provided us with information about the perceptions of the causes of mental illness and help-seeking behaviors of Chinese-speaking Australians. However, to the best of these authors' knowledge, there was only one study that had attempted to systematically explore the nature and level of mental health literacy among Chinese-speaking people.

This study was conducted by Klimidis, Hsiao and Minas which reported that $51 \%$ of Chinese-speaking Australians were able to recognize major depression described in a vignette, that multiple labels were used by the respondents, and that $49 \%$ and $73.6 \%$ of them said that the condition was related to emotional/mental problems and stress, respectively [19]. The authors compared their findings with those of an early study of Jorm and colleagues [4] and concluded that Chinese-speaking Australians did not appear to have a low level of mental health literacy. Their conclusion, however, warrants further validation because the two studies did not use the same vignette and response format to solicit the opinions of the two groups of respondents. In addition, the studies of Ying [14] and Klimidis [19] did not use a cultural perspective to explore the variation in the preference for the type of professional help, medication and treatment method or the conception of mental illness among Chinese-speaking people. Such an understanding would enable the design of culturally relevant public education programs to enhance the mental health literacy of people of Chinese-speaking background in Australia and other countries. In this study, we used the same depression vignette and response format proposed by Jorm et al. [20] and compared our findings with those of Jorm et al. [20] of the mental health literacy of Australian and Japanese people. We chose these two samples for comparison based on the notion that a comparison with the Australian sample might elucidate possible cultural differences in the preference for professional help, medications and treatments between Australians and Chinese-speaking Australians. On the other hand, a comparison with the Japanese sample (who are presumed to be culturally more similar to the Chinesespeaking Australians) might illuminate socioeconomic and policy differences in the preference for professional help, medications and treatments between people in these two countries. Lastly, to explore the cultural 
dimension of the mental health literacy of Chinesespeaking Australians, we added a number of culturally relevant options under the professional help, medication and other treatment categories in the questionnaire.

The adoption of a certain explanatory model of the causes of mental illness affects not only a person's understanding of mental illness but also his or her choice of medication and treatment [20,21]. It is therefore important to explore the cultural conception of mental illness as it is highly related to the mental health literacy of cultural groups. A study conducted by Tang et al. [22] in China found that patients who believed that they had a physical rather than a mental illness tended to seek help from qigong masters or folk healers. Studies conducted by Phillips et al. in China [6] and Wong et al. in Hong Kong [7] revealed that respondents highly endorsed psychosocial explanatory models such as stress, interpersonal conflict and personality deficits in explaining the causes of mental illness. There are, however, very few studies of the cultural conception of mental illness of Chinese-speaking Australians. Among them, Hsiao et al. [21] conducted qualitative research and found that this population combined traditional with Western medical knowledge to develop their own labels for various kinds of mental disorders, which included "mental illness," "physical illness," "normal problems of living" and "psychological problems." Parker and colleagues found that Chinese people tended to deny depression or express it somatically and did not view a depressive episode as a disorder [15-17].

\section{Objectives}

(1) To understand the mental health literacy of Chinese-speaking Australians in Melbourne, Australia. (2) To explore the preference for culturally specific professional help, medications and treatment methods among Chinese-speaking Australians.

(3) To understand the conception of the causes of mental illness of Chinese-speaking Australians.

\section{Methods}

\section{Sample}

This study adopted a cluster convenience sampling method in which subjects were taken from four major areas in metropolitan Melbourne where many Cantonese- and Putongua/Mandarin-speaking Chinese people live: Box Hill, Doncaster, Monash and Preston. The participants were recruited through social services organizations serving the Chinese population in these four areas. Posters in both traditional and simplified Chinese introducing the research were put up on the exhibition boards of these organizations. Potential participants who were interested in the study then approached the research team for further details. Those who decided to participate in the survey signed a consent form and were then given the questionnaire for completion. Selection criteria included: (1) aged 18 or above, and (2) immigrants of Chinese-speaking background who were living in Melbourne, Australia. Respondents took about 40 minutes to complete the questionnaire. The study was approved by the Ethics Committee of the University of Melbourne.

\section{Survey questionnaire}

This instrument covered three areas: sociodemographic characteristics of the respondents, mental health literacy (depression vignette), and Chinese conception of the causes of mental illness.

\section{Mental health literacy}

This instrument was adapted from that used by Jorm et al. [4] to investigate mental health literacy among Australian samples. The original instrument includes depression and schizophrenia vignettes. In this study, only the vignette describing a person with major depression was used [20]. The depression vignette was written to satisfy the diagnostic criteria for major depression according to the fourth edition of the Diagnostic and Statistical Manual of Mental Disorders (DSM-IV) and tenth revision of the International Statistical Classification of Diseases and Related Health Problems (ICD-10). After reading the vignette, respondents answer a series of questions that assess their recognition of the disorder, awareness of mental illness, and beliefs about the helpfulness or harmfulness of different professions, medications and treatment methods. In the first section of this questionnaire, after the depression vignette, respondents are asked to provide written answers to two questions: "Do you think the person needs help or not?" (yes/no format) and "What do you think is wrong with the person?" The main part of the questionnaire is divided into three sections. Respondents are asked to rate each type of (1) professional, (2) medication and (3) treatment as "Helpful," "Harmful" or "Not Sure" in relation to the mental health issue faced by the person in the depression vignette. Based on a literature review [10,23,24] and our clinical experience in working with Chinese people, we added items to the list of options to explore the cultural dimension of the beliefs of respondents about professional help, medications and treatment methods. For example, under Professional Help, "traditional Chinese medicine doctor" and "traditional healer" were added; under Medications, "Chinese herbal medicine"; and under Treatment Methods, "taking Chinese nutritional foods/supplements," "qiqong," "changing fungshui" and "traditional Chinese worship." The English version of the scale was translated into Chinese and back translated into English by an experienced professional translator. Both traditional and simplified Chinese versions of the questionnaire were available for the respondents. 


\section{Chinese conception of the causation of mental illness}

This scale measures the degree to which a respondent agrees or disagrees with different perspectives about the causation of mental illness: hereditary, biochemical, personal, environmental and cultural. It was adapted from that used in a study conducted by Wong et al. [7]. There are 23 items in the original scale, which are divided into two categories: causes of mental illness (e.g., bad fungshui), and the treatment methods associated with the causes of mental illness (e.g., rearranging the household furniture to avoid bad fungshui). However, following a review of the questionnaire conducted by a panel of three community mental health workers who had been working with Chinese people with mental illness, we decided to retain the 13 items that are related to the causes of mental illness and discard those on treatment methods because the latter items overlapped with some in the mental health literacy scale. Items on the causation scale were rated using a 5-point Likert scale ("Absolutely unrelated" (1), "Not related" (2), "Neither related nor unrelated" (3), "Related" (4), "Absolutely related" (5)). The higher is the score, the greater is the belief of the respondent that a certain perspective is related to the causation of mental illness.

\section{Results}

Table 1 shows the demographic characteristics of the sample. There were more females than males $(69.5 \%$ vs. $30.5 \%$, respectively). The majority of the respondents were married, between 40 and 65 years of age, spoke mainly Cantonese or Putonghua/Mandarin, and were relatively well educated, having received senior secondary to tertiary education. Most of them had been born in Hong Kong or China, and migrated to Australia, on average, about 10 years previously. Fifty-six percent had an individual income of less than AUD 20000, and 18\% had an income between AUD 20001 and AUD 40000; it was estimated that the weekly income of individual respondents was around AUD 450. Among them, 41\% rated their English proficiency as average, and over 46\% rated it as poor to very poor. About $40 \%$ of the respondents had full- or part-time jobs, and $25 \%$ were unemployed. The demographic characteristics of our sample were comparable to those of the population of Chinesespeaking Australians and immigrants described in the Australian Census [1] in terms of place of origin, major dialects spoken, length of time in Australia, average annual income and education level. However, in our sample, the male to female ratio was higher and there were more unemployed people [1].

Table 2 shows that although many respondents believed that the person in the vignette needed help, fewer of them compared to those in the other samples [20] identified the condition of the individual as major depression. They were more likely to consider the person to be suffering from stress or anxiety. The respondents in this study also rated professional help as more helpful and less harmful than did their Australian and Japanese counterparts in the study of Jorm et al. [20], and preferred counseling professionals to other professionals or lay helpers, except close family members (see Table 3). The respondents in our sample and the Japanese one both believed close family members to be helpful. Interestingly, although $30 \%$ of the respondents in our sample rated traditional Chinese medicine doctors as helpful, only $2.7 \%$ rated traditional healers as helpful, and $55 \%$ suggested the latter could be harmful (Table 3).

Table 4 shows that Chinese-speaking Australians were more equivocal about the helpfulness or harmfulness of certain medications on the list, especially sleeping pills, antipsychotics and tranquilizers, than the respondents in the study of Jorm et al. [20]. Higher percentages of respondents in the Chinese-speaking Australian and Japanese samples indicated that they were unsure about the usefulness or harmfulness of certain medications compared to the Australian sample. In addition, Australians generally rated medications as more harmful than did either the Chinese-speaking Australians or Japanese. Forty-one percent of Chinese-speaking Australians indicated that antidepressants would be helpful to the person in the vignette, compared to $34.8 \%$ and $46.7 \%$ of Japanese and Australians, respectively. Lastly, $17.4 \%$ of the respondents in the present study rated Chinese herbal medications as helpful. However, a similar percentage thought that they could be harmful (Table 4).

Both our subjects and the Australians in the study of Jorm et al. [20] highly endorsed the notion of lifestyle changes (i.e., engage in physical activities, get out more, learn to relax) as helpful for the person in the vignette (Table 5). However, the percentages in these areas were lower among the Japanese sample. Psychotherapy was also rated very highly by our respondents, more so than that in either the Australian or the Japanese sample. In our study, about $33 \%$ and $27 \%$ of the respondents considered consuming Chinese nutritional foods/supplements and practicing qiqong, respectively, to be helpful, whereas very few perceived changing fungshui or traditional Chinese worship to be helpful. About half of the respondents indicated that traditional Chinese worship was harmful (Table 5).

Table 6 documents the conceptions of the respondents in this study of the causes of mental illness. Items related to psychosocial perspective were rated highly, including life stress, negative life experience and interpersonal conflict. Personality factors including introverted personality and "think too much" also received high ratings. Traditional beliefs such as "punishment for misdeeds conducted by ancestors" and "demon 
Table 1 Demographic characteristics of the respondents $(N=200)$

\begin{tabular}{|c|c|c|c|}
\hline & Item & $\mathbf{N}$ & $\%$ \\
\hline \multirow[t]{2}{*}{ Gender } & Male & 61 & 30.5 \\
\hline & female & 139 & 69.5 \\
\hline Age & & Mean age $=49.2$ Range $=19$ to 78 years old & \\
\hline \multirow[t]{7}{*}{ Education } & Primary school & 6 & 3 \\
\hline & Secondary school & 23 & 11.5 \\
\hline & Senior secondary school & 57 & 28.5 \\
\hline & Diploma & 48 & 24 \\
\hline & Bachelor's degree & 38 & 19 \\
\hline & Master's degree or higher & 12 & 6 \\
\hline & Unknown & 16 & 8 \\
\hline Living in Australia (months) & & Mean stay $=125$ months Range $=1$ to 456 months & \\
\hline \multirow[t]{6}{*}{ Place of origin } & China & 86 & 43 \\
\hline & Hong Kong & 64 & 32 \\
\hline & Vietnam & 13 & 6.5 \\
\hline & Singapore/Malaysia & 18 & 9 \\
\hline & Taiwan & 16 & 8 \\
\hline & Other & 3 & 1.5 \\
\hline \multirow[t]{5}{*}{ Marital status } & Single & 24 & 12 \\
\hline & Married & 132 & 66 \\
\hline & Widow & 13 & 3.5 \\
\hline & Divorced & 24 & 11 \\
\hline & Cohabitating & 7 & 7.5 \\
\hline \multirow[t]{6}{*}{ Personal income per year } & $0-20000$ & 112 & 56 \\
\hline & $20001-40000$ & 36 & 18 \\
\hline & $40001-60000$ & 17 & 8.5 \\
\hline & $60001-80000$ & 9 & 4.5 \\
\hline & over 80001 & 2 & 1 \\
\hline & Unknown & 24 & 12 \\
\hline \multirow[t]{5}{*}{ Language } & Cantonese & 136 & 68 \\
\hline & Putonghua/Mandarin & 52 & 26 \\
\hline & Hakka & 4 & 2 \\
\hline & Chiu Chou & 3 & 1.5 \\
\hline & Other & 5 & 2.5 \\
\hline \multirow[t]{5}{*}{ English ability } & Very poor & 30 & 15 \\
\hline & Poor & 63 & 31.5 \\
\hline & Average & 82 & 41 \\
\hline & Good & 18 & 9 \\
\hline & Very good & 7 & 3.5 \\
\hline \multirow[t]{7}{*}{ Employment } & Full time & 40 & 20 \\
\hline & Part time & 41 & 20.5 \\
\hline & Seeking employment & 37 & 18.5 \\
\hline & Unemployed & 50 & 25 \\
\hline & Retired & 9 & 4.5 \\
\hline & Housewife & 11 & 5.5 \\
\hline & Unknown & 12 & 6 \\
\hline
\end{tabular}


Table 2 Percentage of respondents giving labels to the depression vignette and seeing that the person needed help

\begin{tabular}{lccc}
\hline Item & Australian & Japanese & Chinese Australian \\
\hline Label & $\%$ & $\%$ & $\%$ \\
Depression & 65.3 & 22.6 & $14(\mathrm{n}=28)$ \\
Stress/anxiety & 16.6 & 25 & $26.5(\mathrm{n}=53)$ \\
Emotional disturbance & 4.5 & 29.4 & $7.5(\mathrm{n}=15)$ \\
Insomnia/lack of concentration & NA & NA & $8(\mathrm{n}=16)$ \\
No answer & NA & NA & $44(\mathrm{n}=88)$ \\
Needing help & & & $90.6(\mathrm{n}=181)$ \\
Yes & & & $9.4(\mathrm{n}=19)$ \\
No & & & \\
\hline
\end{tabular}

possession" had the lowest ratings. The findings indicate that the Chinese-speaking Australians in this sample endorsed psychosocial rather than traditional perspectives of the causes of mental illness.

\section{Discussion}

Lower percentage of depression literacy among Chinesespeaking Australians

In this study, only $14 \%$ of the respondents were able to correctly label the depression vignette, a figure that is much lower than the $67.6 \%$ for the Australian sample and slightly lower than the $22.6 \%$ observed in the Japanese sample of Jorm et al. [20]. One reason for this relatively low percentage may be related to the Chinese conception of mental illness. In recent years, there is growing evidence to suggest that Chinese people tend to view mental illness as a reflection of one's "inability to deal with social stress," "interpersonal conflict" or "personality deficits" $[6,7]$. Thus, it is not surprising to find that there were so few Chinese-speaking Australians in our sample who could correctly label the vignette as a case of major depression; 34\% said that the person in the vignette suffered from stress/anxiety or an emotional disturbance. Indeed, our findings on the conceptions of Chinese-speaking Australians of the causes of mental illness support the abovementioned finding of other studies that Chinese-speaking Australians tend to adopt psychosocial and biochemical rather than traditional perspectives.

However, it is important to note that $44 \%$ of the respondents did not give the depression vignette any label, which might have deflated the percentage of the correct identification of the condition. It is possible that some of these respondents did know the answer, but were unsure of what label to give to the vignette and consequently chose not to give one. In the future, an answering format other than an open-ended question format may be needed to determine whether the respondent can correctly label the depression vignette.

Table 3 Percentage of respondents rating each type of professional as "helpful" or "harmful" for the person in the depression vignette (by sample)

\begin{tabular}{|c|c|c|c|c|c|c|}
\hline \multirow[t]{3}{*}{ Item } & \multicolumn{3}{|c|}{$\%$} & \multicolumn{3}{|c|}{$\%$} \\
\hline & Helpful & & & Harmful & & \\
\hline & Australian & Japanese & Chinese Australian & Australian & Japanese & Chinese Australian \\
\hline 1. Doctor & 87.3 & 30.4 & 74 & 0.5 & 9.4 & 2.1 \\
\hline 2. Pharmacist & 35.4 & 6.8 & 27.6 & 8.7 & 23.6 & 8.6 \\
\hline 3. Counselor & 82.2 & 85.8 & 90.2 & 3.1 & 1.0 & 0.5 \\
\hline 4. Social worker & 62.8 & 73.4 & 86.9 & 4.5 & 1.4 & 1.0 \\
\hline 5. Hot-line telephone counselor & 63.5 & 42.4 & 77.4 & 5.9 & 8.6 & 1.1 \\
\hline 6. Psychiatrist & 65.0 & 69.4 & 73.5 & 7.1 & 5.4 & 3.7 \\
\hline 7. Clinical psychologist & 66.9 & 56.6 & 83.6 & 5.1 & 6.0 & 0 \\
\hline 8. Close family members & 67.9 & 85 & 82.2 & 4.9 & 1.6 & 2.1 \\
\hline 9. Close friends & 78.2 & 84.8 & 76.4 & 2.1 & 1.8 & 2.6 \\
\hline 10. Naturopath & 34.9 & 11.2 & 39.2 & 11.1 & 18.8 & 4.2 \\
\hline 11. Religious practitioner & 45.3 & 13.6 & 58.5 & 8.1 & 24.2 & 2.1 \\
\hline 12. Deal with it alone & 13.1 & 24.4 & 28.2 & 64 & 41.4 & 61.7 \\
\hline 13. Traditional Chinese medicine doctor & NA & NA & 31.8 & NA & NA & 8.0 \\
\hline 14. Traditional healer & NA & NA & 2.7 & NA & NA & 54.9 \\
\hline
\end{tabular}


Table 4 Percentage of respondents rating each type of medication as "helpful" or "harmful" for the person in the depression vignette (by sample)

\begin{tabular}{|c|c|c|c|c|c|c|}
\hline \multirow[t]{3}{*}{ Item } & \multicolumn{3}{|c|}{$\%$} & \multicolumn{3}{|c|}{$\%$} \\
\hline & Helpful & & & Harmful & & \\
\hline & Australian & Japanese & Chinese Australian & Australian & Japanese & Chinese Australian \\
\hline 1. Vitamins, minerals & 50.2 & 20.2 & 26.8 & 4.4 & 14.6 & 5.7 \\
\hline 2. St. John's wort & NA & NA & 2.6 & NA & NA & 17.5 \\
\hline 3. Pain relievers & 14.8 & 4.4 & 6.8 & 37.7 & 43.4 & 55.7 \\
\hline 4. Antidepressants & 46.7 & 34.8 & 40.9 & 27.5 & 18.2 & 14 \\
\hline 5. Antibiotics & 10.4 & 6.2 & 37.5 & 38.3 & 29.8 & 4.4 \\
\hline 6. Sleeping pills & 23.9 & 31.6 & 31.1 & 49.6 & 27.0 & 31.1 \\
\hline 7. Antipsychotics & 11.2 & 22.6 & 27.5 & 48.3 & 19 & 25.9 \\
\hline 8. Tranquilizers & 13.8 & 38.4 & 26.4 & 60.4 & 15.8 & 29.0 \\
\hline 9. Chinese herbal medicines & NA & NA & 17.4 & NA & NA & 18.5 \\
\hline
\end{tabular}

Endorsement of a psychosocial perspective and its influence on preferences for professional help, medications and treatment methods

In this study, Chinese-speaking Australians tended to rate counseling professionals (e.g., counselors, social workers, hot-line telephone counselors and clinical psychologists) as helpful, and the percentages of perceived helpfulness of these groups were higher than those found in either the Australian or the Japanese sample in the study of Jorm et al. [20]. Again, this may reflect the current view held by Chinese-speaking Australians that depression is caused by psychosocial problems such as stress or personality-related issues. Therefore, individuals with psychosocial problems are seen as unhappy or sad, and to require the opportunity to talk about their troubles and obtain support and assistance through counseling.

Another piece of evidence regarding psychosocial perspectives is the high rating of Chinese-speaking
Australians of lifestyle changes (i.e., engage in physical activities, get out more, learn to relax) as helpful for the person in the vignette. In modern society, being active is a sign of good health. Individuals pay to participate in physical and relaxation activities such as going to the gym, doing Pilates or getting a massage to feel good and relax. These treatment methods fit the belief held by Chinese-speaking Australians that depression is a psychosocial issue and that one can overcome unhappiness through lifestyle modification.

Endorsement of a medical perspective and its influence on preferences for professional help, medications and treatment methods

Over $70 \%$ of the Chinese-speaking Australians considered family doctors or GPs to be helpful, and this figure is comparable to that of the Australian sample. The Chinese-speaking Australians in our sample have lived in Australia for an average of more than 10 years. Thus, they may have become acculturated to Australian

Table 5 Percentage of respondents rating each type of intervention as "helpful" or "harmful" for the person in the depression vignette (by sample)

\begin{tabular}{|c|c|c|c|c|c|c|}
\hline & Australian & Japanese & Chinese Australian & Australian & Japanese & Chinese Australian \\
\hline 1. Physical activity & 92.0 & 69.4 & 97.5 & 0.8 & 3.6 & 0.5 \\
\hline 2. Read about problem & 79.3 & 60 & 64.6 & 4.1 & 7.6 & 4.1 \\
\hline 3. Get out more & 87.0 & 67.0 & 60.2 & 0.4 & 3.0 & 8.9 \\
\hline 4. Learn to relax & 83.6 & 38.0 & 83.1 & 1.5 & 7.6 & 0 \\
\hline 5. Cut out alcohol & 56.0 & 10.0 & 82.6 & 4.7 & 17.2 & 4.6 \\
\hline 6. Psychotherapy & 44.1 & 49.0 & 89.8 & 10.0 & 7.4 & 0 \\
\hline 7. Cognitive behavioral treatment & NA & NA & 69.6 & NA & NA & 0.5 \\
\hline 8. Hypnosis & 22.4 & 28.0 & 27.8 & 17.0 & 14.2 & 7.2 \\
\hline 9. Psychiatric ward & 16.4 & 13.6 & 15.0 & 53.3 & 43.0 & 34.2 \\
\hline 10. Electroconvulsive treatment (ECT) & 5.9 & 2.2 & 9.4 & 69.4 & 50.2 & 16.1 \\
\hline 11. Occasional drink & 44.4 & 31.4 & 10.3 & 15.4 & 17.4 & 44.1 \\
\hline 12. Taking Chinese nutritional foods/supplements & NA & NA & 32.6 & NA & NA & 11.9 \\
\hline 13. Qigong & NA & NA & 26.9 & NA & NA & 9.3 \\
\hline 14. Changing fungshui & NA & NA & 5.8 & NA & NA & 27.7 \\
\hline 15. Traditional Chinese worship & NA & NA & 4.2 & NA & NA & 51.6 \\
\hline
\end{tabular}




\begin{tabular}{|c|c|}
\hline Item & Mean \\
\hline 1. Life stress (e.g. work, study or finance) & 4.10 \\
\hline 2. Introverted personality & 3.90 \\
\hline 3. Negative life experience & 3.89 \\
\hline 4. Think too much & 3.83 \\
\hline 5. Chemical imbalance in the brain & 3.63 \\
\hline 6. Genetic pre-disposition & 3.63 \\
\hline 7. Interpersonal conflicts & 3.47 \\
\hline 8. Too much qiqong practice & 2.52 \\
\hline 9. Yin Yang Imbalance & 2.51 \\
\hline 10. Fate & 1.93 \\
\hline 11. Demon possession & 1.68 \\
\hline 12. Punishment for the misdeed conducted by ancestors & 1.61 \\
\hline 13. Bad Fung Shui & 1.58 \\
\hline
\end{tabular}

healthcare practice, in which a family doctor or GP is the first point of contact and gives referrals for specialized mental health services. In contrast, a fairly low percentage of respondents in the Japanese sample considered a family doctor or GP to be helpful. Jorm et al. [20] suggested, "In Japan, the interest of family doctors and GPs in psychiatric treatment is not necessarily great, and it is difficult to say that their ability to diagnose psychiatric patients correctly is sufficient." Given these findings about the perceived helpfulness of GPs, family doctors and counseling professionals, it is essential to educate GPs and family doctors in Australia about the perceptions of the causes of mental illness and preferred choice of professionals, medications and treatment methods of the Chinese-speaking population. In addition, they should be given a list of English-speaking and Chinese-speaking counseling professionals who provide services in their nearby areas so that prompt referrals can be made.

Although similar percentages of Chinese-speaking Australians and Australians rated antidepressants as helpful for the person in the depression vignette, the former were more equivocal and unsure about the helpfulness or harmfulness of certain medications, including sleeping pills, antipsychotics and tranquilizers, compared to the latter, who perceived that most of the medications were harmful rather than helpful. Such differences may reflect the difference in the level of knowledge of medications between the two groups. In Australia, GPs and pharmacists are obliged to inform their patients of the effects and side effects of medications, and Australians are generally well informed about the medications that they are taking. These patients are also more aware of their rights and more forthright in requesting information about medication from professionals. However,
Chinese Confucian ethics advocate a respect for authority [22], and thus Chinese-speaking patients do not normally ask questions about the medications that they have been prescribed; rather, they simply accept what they have been given. A further barrier to knowledge about medication is that the labels and information on Western medicine are written in English and often use technical terms, making them less accessible and less easily understood by the general population of Chinesespeaking people. Although the Chinese-speaking Australians in our sample have lived in Australia for many years, the abovementioned factors contribute to their lack of knowledge about medications. Thus, it is advisable to educate Chinese-speaking Australians about the effects and side effects of medications so that they can distinguish the different types of medicines used to treat psychiatric illnesses. To help this population to better understand the medications that they are given, technical and medical terms should be avoided as much as possible and plain and ordinary language used instead.

\section{The influence of traditional values on preferences for} professional help, medications and treatment methods

The percentage of Japanese and of Chinese-speaking Australians who endorsed close family members as helpful to the person in the depression vignette was higher than that of Australians. It is suggested that collectivism may explain the similarity between the Japanese and Chinese-speaking samples. Many studies have found that in societies with a collectivist and familial orientation, such as Japan and China, there is a tendency for people to rely heavily on their families and other close members of informal networks for support [25]. According to Wong [10], individuals in these societies do not make decisions solely on their own regarding the presence or absence of a mental illness or about seeking help from external sources; rather, they have to consider the views of different members, especially elders, before reaching a decision. Because family plays an important role in the lives of members in societies such as Japan and China, it is not surprising to find that a high percentage of first-generation Chinese-speaking Australians indicated that family members would be helpful to the person in the depression vignette.

About 30\% of Chinese-speaking Australians perceived traditional Chinese medicine doctors, Chinese nutritional foods/supplements and qiqong to be helpful. Traditional Chinese medicine is widely practiced in China, Hong Kong and Taiwan, and is well respected by many Chinese. In Australia, there has been an increase in the number of traditional Chinese medicine clinics in recent years. Indeed, Chinese people do not see traditional Chinese medicine and Western medicine as incompatible [26]. Rather, they believe that Chinese medicine is useful in maintaining health and preventing illness from 
occurring. In China, it is not uncommon for both Western and Chinese medicine to be used to treat certain illnesses. Therefore, it is important not only to educate Chinese-speaking Australians about the advantages and disadvantages of taking Chinese herbal medicines and other treatments such as qiqong alongside Western medication but also to provide traditional Chinese medicine doctors in Australia with knowledge of psychiatric illness and mental health services so that they can be equipped to conduct initial psychiatric assessment and refer clients to GPs/family doctors so that the latter can make appropriate mental health referrals.

\section{Limitations}

This study adopted a cluster convenience sampling method to recruit Chinese-speaking Australians in Melbourne, Australia. The research team is aware of the limitations of convenience sampling and would have preferred to use a random sampling strategy; however, this was impossible because of limited resources. To enhance the representativeness of the sample, subjects were recruited from four major areas in Melbourne where most Chinese live. However, only those who accessed the various community social services were included. Individuals who did not participate in the activities or take advantage of the services offered by these social services centers or drop by the centers would not be aware of this research project and thus are excluded from the study. Therefore, the findings might be specific to a group of relatively active Chinese-speaking participants who use the social services centers in these four areas in Melbourne, Australia. In addition, as the research was conducted in Melbourne, the results might not be generalizable to Chinese-speaking people living in other parts of Australia or overseas. Although this study used the same questionnaire and response format proposed by Jorm et al. [20], we do not know whether our sample resembles the Australian and Japanese samples of the latter study because their demographic characteristics were not given. In addition, even if the demographic characteristics are comparable, subtleties of meaning and cultural factors may influence the results of our study, and in turn, affect the interpretation of the comparison data.

\section{Conclusion}

This study reveals the pre-existing and culturally and socially driven beliefs about mental illness, professional help, medications and treatment methods held by a group of Chinese-speaking Australians in Melbourne, Australia. Campaigns to increase the mental health literacy of Chinese-speaking Australians need to take into account these beliefs so that culturally relevant mental health education programs can be developed.

\section{Acknowledgements}

Dr Wong would like to express his sincere thanks to Professor Anthony Jorm for his generous support in the early stage of the research process and in the preparation of this manuscript.

\section{Author details}

${ }^{1}$ School of Nursing and Social Work, Faculty of Medicine, Dentistry and Health Sciences, University of Melbourne, Level 5, 234 Queensberry Street, Carlton, Melbourne, Victoria, 3053, Australia. ${ }^{2}$ Centre for Cognitive Behavioural Therapy and Training for Chinese People, Department of Social Work and Social Administration, University of Hong Kong, Hong Kong, PR China. ${ }^{3}$ Community Settlement Services, Chinese Community Social Services Centre Inc., Melbourne, Victoria, Australia.

\section{Authors' contributions}

FKDW initiated the research, translated and drafted the questionnaire analyzed the data and wrote the first draft of the manuscript. YKAL contributed ideas to the design of the questionnaire and commented on the draft of the manuscript. AP and her agency helped out in the data collection. All authors have read the final manuscript and approved its contents.

\section{Authors' Information}

Fu Keung Daniel Wong, School of Nursing and Social Work, Faculty of Medicine, Dentistry and Health Sciences, University of Melbourne, Level 5, 234 Queensberry Street, Carlton, Melbourne, Victoria, Australia, 3053. Telephone: (613) 8344-9408; fax: (613) 9347-4375; e-mail: fwong@unimelb. edu.au (Corresponding author)

Yuk Kit Angus Lam, Centre for Cognitive Behavioural Therapy and Training for Chinese People, Department of Social Work and Social Administration, University of Hong Kong, Hong Kong, China. E-mail: anguslyk@hku.hk Ada Poon, Community Settlement Services, Chinese Community Social Services Centre Inc., Melbourne, Victoria, Australia. E-mail: ada@ccssci.com.au

\section{Competing interests}

The authors declare that they have no competing interests.

Received: 27 July 2009

Accepted: 19 January 2010 Published: 19 January 2010

\section{References}

1. Multicultural Affairs Branch and the Programme Statistics and Monitoring Section of DIAC, selected information from Census statistics 2001. 2006http://www.immi.gov.au/media/publications/statistics/ popflows2006-7/.

2. Lam AP, Kavanagh DJ: Help-seeking by immigrant IndoChinese psychiatric patients in Sydney, Australia. Psych Services 1996, 47:993-995.

3. Ryder AG, Bean G, Dion KL: Caregiver responses to symptoms of firstonset psychosis: A comparison study of Chinese and Euro-Canadian families. Transcultural Psychiatry 2000, 37:225-235.

4. Jorm AF, Korten AE, Jacomb PA, Rodgers B, Pollitt P, Christensen $H_{\text {, }}$ Henderson S: Helpfulness of interventions for mental health disorders: Beliefs of health professionals compared with the general public. $\mathrm{Br} \mathrm{J}$ Psychiatry 1997, 17:233-237.

5. Jorm AF, Christensen H, Griffiths KM: The public's ability to recognize mental disorders and their beliefs about treatment: Changes in Australia over 8 years. ANZ J Psychiatry 2006, 40:36-41.

6. Phillips MR, Li YY, Stroup S, Xin LH: Causes of schizophrenia reported by patients' family members in China. Br J Psychiatry 2000, 177:20-25.

7. Wong FKD, Tsui HKP, Pearson V, Chen EYH, Chiu SN: Family burdens, Chinese health beliefs, and the mental health of Chinese caregivers in Hong Kong. Transcultural Psychiatry 2004, 41:497-513.

8. Chou KL, Mak KY: Attitudes to mental patients among Hong Kong Chinese: A trend study over two years. International J Soc Psychiatry 1998, 44:215-224.

9. Fung KMT, Tsang HWH, Corrigan PW, Lam CS, Cheng WM: Measuring selfstigma of mental illness in China and its implications for recovery. International J Soc Psychiatry 2007, 53:408-418.

10. Wong FKD: Crucial individuals in the help-seeking pathway of the Chinese caregivers with relatives suffering from early psychosis in Hong Kong: Implications for social work practice. Social Work 2007, 52:127-138. 
11. Kung WW: Cultural and practical barriers to seeking mental health treatment for Chinese migrants. J Com Psychology 2004, 32:27-43.

12. Jorm AF: Mental health literacy: Public knowledge and beliefs about mental disorders. Br J Psychiatry 2000, 177:396-401.

13. Wang JL, Adair C, Fick G, Lai D, Evans B, Perry BW, Jorm AF, Addington D: Depression literacy in Alberta: Findings from a general population sample. Can J Psychiatry 2007, 52:442-449.

14. Ying Y: The conception of depression in Chinese Americans. Asian American mental health: Assessment theories and methods New York: Kluwer Academic PublishersKurasaki KS, Okazaki S, Sue S 2002, 173-184.

15. Parker G, Gladstone G, Chee KT: Depression in the planet's largest ethnic group: The Chinese. Am J Psychiatry 2001, 158:857-864.

16. Parker G, Chan B, Tully L: Depression and help-seeking in a Western sample of "highly acculturated" Chinese and controls. J Affective Disord 2006, 239-242.

17. Chan B, Parker G: Some recommendations to assess depression in Chinese people in Australasia. ANZ J Psychiatry 2004, 141-147.

18. Blignault $L$, Ponzio $V$, Rong $Y$, Maurice $E$ : A qualitative study of barriers to mental health services utilization among migrants from mainland China in South-East Sydney. Int I Soc Psychiatry 2008, 54:180-190.

19. Klimidis S, Hsiao FH, Minas IH: Chinese-Australians' knowledge of depression and schizophrenia in the context of their under-utilization of mental health care: An analysis of labeling. International I Soc Psychiatry 2007, 53:464-479.

20. Nakane Y, Jorm AF, Yoshioka K, Christensen H, Nakane H, Griffiths KM: Public beliefs about treatment and outcome of mental disorders: A comparison of Japan and Australia. BMC Medicine 2005, 5:33.

21. Hsiao FH, Klimidis S, Minas IH: Folk concepts of mental disorders among Chinese-Australian patients and their caregivers. Journal of Advanced Nursing 2006, 55:58-67.

22. Tang YL, Sevigny R, Mao PX, Jiang F, Cai Z: Help-seeking behaviours of Chinese patients with schizophrenia admitted to a psychiatric hospital. Admin and Policy in Mental Health and Mental Health Services Res 2007, 34:101-107.

23. Kleinman A: Social origins of distress and disease: Depression, neurasthenia and pain in modern China. New Haven: Yale University Press 1986.

24. Liu X: Psychiatry in traditional Chinese medicine. Br J Psychiatry 1981, 138:429-433.

25. Lai DWL, Surwood S: Chinese health beliefs of older Chinese in Canada. J Aging and Health 2009, 21:38-62.

26. Lam TP: Strengths and weaknesses of traditional Chinese medicine and Western medicine in the eyes of some Hong Kong Chinese. J Epidem and Com Health 2001, 55:762-765.

\section{Pre-publication history}

The pre-publication history for this paper can be accessed here:http://www biomedcentral.com/1471-244X/10/7/prepub

doi:10.1186/1471-244X-10-7

Cite this article as: Wong et al:: Depression literacy among Australians of Chinese-speaking background in Melbourne, Australia. BMC Psychiatry $201010: 7$.

\section{Submit your next manuscript to BioMed Central and take full advantage of:}

- Convenient online submission

- Thorough peer review

- No space constraints or color figure charges

- Immediate publication on acceptance

- Inclusion in PubMed, CAS, Scopus and Google Scholar

- Research which is freely available for redistribution 